\title{
Precipitation and grain growth modelling in Ti-Nb microalloyed steels.
}

\author{
Alexis Graux ${ }^{\mathrm{a}, *}$, Sophie Cazottes ${ }^{\mathrm{a}}$, David De Castro ${ }^{\mathrm{b}}$, David San Martín ${ }^{\mathrm{b}}$, Carlos Capdevila ${ }^{\mathrm{b}}$, Jose Maria \\ Cabrera $^{c}$, Sílvia Molas ${ }^{\mathrm{d}}$, Sebastian Schreiber ${ }^{\mathrm{e}}$, Djordje Mirkovićf ${ }^{\mathrm{f}}$, Frédéric Danoix ${ }^{\mathrm{g}}$, Matthieu Bugnet ${ }^{\mathrm{a}}$, \\ Damien Fabrègue ${ }^{\mathrm{a}}$, Michel Perez ${ }^{\mathrm{a}}$ \\ ${ }^{a}$ Université de Lyon, INSA-Lyon, MATEIS CNRS UMR5510, 69621 Villeurbanne Cedex, France. \\ ${ }^{b}$ Materalia Research Group, Centro Nacional de Investigaciones Metalúrgicas (CENIM-CSIC), Avda Gregorio del Amo 8, \\ Madrid E-28040, Spain. \\ ${ }^{c}$ Polytechnic University of Catalonia, Av. Diagonal, EEBE, c/Eduard Maristany 10-14, 08019 Barcelona, Spain. \\ ${ }^{d}$ Fundació CTM Centre Tecnològic, Avda Bases de Manresa, 1, 08242 Manresa, Spain. \\ ${ }^{e}$ Thyssenkrupp Steel Europe AG, Kaiser-Wilhelm-Strae 100, 47166 Duisburg, Germany. \\ ${ }^{f}$ Salzgitter Mannesmann Forschung GmbH, Eisenhttenstrasse 99, 38239, Salzgitter, Germany. \\ ${ }^{g}$ Groupe de Physique des matériaux (GPM), Avenue de l'Université, 76800 Saint Etienne du Rouvray, France
}

\begin{abstract}
Mechanical properties of microalloyed steels are enhanced by fine precipitates, that ensure grain growth control during subsequent heat treatment. This study aims at predicting austenite grain growth kinetics coupling a precipitation model and a grain growth model. These models were applied to a titanium and niobium microalloyed steel. The precipitate size distributions were first characterized by TEM and SEM and prior austenite grain boundaries were revealed by thermal etching after various isothermal treatments. From CALPHAD database, a solubility product was determined for $(\mathrm{Ti}, \mathrm{Nb}) \mathrm{C}$ precipitates. A numerical model based on the classical nucleation and growth theories was used to predict the time evolution of $(\mathrm{Ti}, \mathrm{Nb}) \mathrm{C}$ size distributions during various isothermal heat treatments. The precipitation model was validated from TEM/SEM analysis. The resulting precipitate size distributions served as entry parameters to a simple grain growth model based on Zener pinning. The pinning pressure was calculated using the whole size distribution. The resulting austenite grain growth kinetics were in good agreement with the experimental data obtained for all investigated heat treatments.
\end{abstract}

Keywords: Microalloyed steels, Precipitation, Austenite, Grain growth, Modelling

\section{Introduction}

Microalloying elements such as titanium and niobium form precipitates enhancing the mechanical properties of steels by controlling austenite grain growth [1] and through precipitation hardening [2].

\footnotetext{
${ }^{*}$ Corresponding author.

Email address: alexisgraux@msn.com (Alexis Graux)
}

Regardless of the intended phase transformation from the austenite domain, the resulting mechanical properties depend on the prior austenite grain size. Indeed, austenite grain boundaries act as nucleation sites for ferrite, bainite and/or martensite. A finer austenite microstructure thus results in a finer ultimate microstructure, with enhanced strength and toughness. 
During hot rolling process, the soaking temperature prior to hot rolling must be carefully selected to optimize the effects of microalloying elements. A high soaking temperature ensures a complete dissolution of the pre-existing precipitates, leading to the formation of finer precipitates during and after hot rolling. However, it also results in coarser austenite microstructures. On the other hand, a low soaking temperature would maintain a fine austenite structure but may not dissolve existing coarse precipitates, decreasing the potential for precipitation strengthening during the following steps. The choice of the soaking temperature and duration is generally the result of many years of practical feedback. There is a demand to replace an essentially experience-based approach with thermodynamic and kinetic models.

Grain growth is an important field of study in materials science and has been the subject of a considerable amount of work $[3,4]$. In microalloyed steels, microalloying elements may interact with the motion of grain boundary in two ways. In the first place, a dispersion of precipitates exerts a retarding pressure on grain boundary, which has a pronounced effect on grain growth. The magnitude of this effect depends on the size, shape and volume fraction of precipitates $[1,5]$. Secondly, a migrating interface drags a local segregation (atmosphere) of solute elements, which exerts a retarding force on it. Thus, solute elements may reduce largely reduce the grain boundary mobility. This phenomenon is generally referred to as solute drag effect $[6,7]$. In the case of high velocity grain boundaries, the solute elements can no longer keep up with the grain boundaries. Thus, the solute drag stays limited in the case of high temperature heat treatments.

Numerous studies intend to develop numerical models for austenite grain growth kinetics in steels. Phenomenological approaches are widely used for their simplicity [8-13], the grain diameter following empirical equations of the type:

$$
D^{n}-D_{0}^{n}=A t \exp \left(\frac{-Q_{G G}}{R_{g} T}\right)
$$

where $D$ is the final grain diameter, $D_{0}$ is the initial grain diameter, $A$ and $n$ are empirical parameters, $Q_{G G}$ is the activation energy for grain growth, $R_{g}$ is the gas constant, $T$ is the temperature, and $t$ is the soaking duration. However, these types of models do not take the pinning effect of precipitates into account. Other studies adopt physically based approaches that account for the influence of pinning precipitates on grain growth [14-17]. The austenite grain size is shown to result from the competition between a driving pressure for grain growth and a pinning pressure induced by precipitates that evolves during heat treatments. In particular, Banerjee et al. [16] and Maalekian et al. [17] present models coupling the evolution of precipitation with austenite grain growth. The pinning effect of different precipitate species are added up to calculate the global pinning pressure. Although Maalekian et al. [17] present a multi-class description of the precipitation state, the pinning pressures are calculated using the mean volume fraction $f$ of precipitate, and the mean radius of precipitates $r$. More recently, Razzak et al. [18, 19] showed the importance of using the size distribution of precipitates for the calculation of pinning pressure in an abnormal grain growth model. Considering only averaged values may lead to erroneous calculated 
pinning pressure, especially in cases where precipitate size distribution is broad and/or bimodal.

The present work aims at coupling a KampmannWagner Numerical (KWN) type precipitation model [20] with a grain growth model to predict the austenite grain size obtained after several heat treatments. The evolution of a pre-existing population of $(\mathrm{Ti}, \mathrm{Nb}) \mathrm{C}$ precipitates was modeled using a multi-class description of the precipitation state. This work differs from the aforementioned studies by considering the effect of the whole size distribution of precipitates instead of using mean parameters $f$ and $r$ for calculating the pinning pressure. Thermodynamic databases were used, accounting for the alloy thermal history, to estimate the solubility product of $(\mathrm{Ti}, \mathrm{Nb}) \mathrm{C}$ precipitates.

\section{Experimental procedure}

\subsection{Alloy production}

The alloy used in this study was produced by vacuum induction melting. An ingot of approximate dimensions $140 \times 150 \times 50 \mathrm{~mm}^{3}$ was obtained. The ingot was reheated at $1200{ }^{\circ} \mathrm{C}$ for 2 hours before hot rolling. Seven passes were applied, giving a plate of $450 \times 150 \times 15 \mathrm{~mm}^{3}$. The alloy composition was measured by inductively coupled plasma mass spectrometry (ICP-MS). The key alloying elements are listed in Table 1.

\subsection{Grain growth measurements}

A Bähr 805 DIL dilatometer was used to perform heat treatments consisting of a $5{ }^{\circ} \mathrm{C} / \mathrm{s}$ ramp up to the austenitisation temperature $T_{A}\left(950^{\circ} \mathrm{C}<\right.$ $T_{A}<1250{ }^{\circ} \mathrm{C}$ ), followed by a $10 \mathrm{~min}$ holding at $T_{A}$ and cooling. The temperature was controlled by welding a type $\mathrm{K}$ thermocouple in the middle of the samples. Cylindrical samples of $10 \mathrm{~mm}$ length and $4 \mathrm{~mm}$ diameter were machined from the steel plate and used to determine austenite grain sizes. For all temperatures except $1250^{\circ} \mathrm{C}$, the austenite grain size was determined by the thermal etching method [21]. After austenitisation, the heating was switched off, and the samples cooled down to room temperature with an average cooling rate of $10^{\circ} \mathrm{C} / \mathrm{s}$. A $2 \mathrm{~mm}$ wide flat surface was prepared along the sample length by mechanical grinding and polishing, finishing with $1 \mu \mathrm{m}$ diamond solution. During the heat treatments, grooves were formed at the intersection of austenite grain boundaries with the flat surface $[22,23]$. At $1250^{\circ} \mathrm{C}$, thermal etching turned out to be unsuccessful, and a BéchetBeaujard etching [24] was performed instead. Since a martensitic microstructure is needed for BéchetBeaujard etching, the sample was quenched (cooling rate of $100^{\circ} \mathrm{C} / \mathrm{s}$ ) with helium after the isothermal holding at $1250^{\circ} \mathrm{C}$.

Etched samples were then observed using a Nikon Epiphot 200 optical microscope. For the thermally etched samples, Nomarski microscopy under bright field reflection illumination has been used. This technique allows highlighting microtopographic features, like the thermal grooves [25]. In order to avoid any inaccuracies on the temperature measurement due to the temperature gradient of the dilatometer, observations were performed on the same layer where the thermocouple was welded. The areas of at least 50 grains were determined using FIJI [26] by manual detouring. The equivalent area diameter $D_{A}$ of a circular grain was calculated 


\begin{tabular}{ccccccc}
\hline Element & $\mathrm{C}$ & $\mathrm{Mn}$ & $\mathrm{Ti}$ & $\mathrm{Nb}$ & $\mathrm{S}$ & $\mathrm{N}$ \\
\hline wt\% & 0.062 & 1.910 & 0.085 & 0.039 & 0.003 & 0.006 \\
\hline at\% & 0.286 & 1.927 & 0.098 & 0.023 & 0.005 & 0.024 \\
\hline
\end{tabular}

Table 1: Composition of the studied steel (Key alloying elements) determined by ICP-MS

from each measured grain area $A$ :

$$
D_{A}=\sqrt{\frac{4 A}{\pi}}
$$

The mean grain size $D$ was estimated by multiplying the number-based mean equivalent area diameter $D_{A}$ by 1.2 , in accordance with [27].

\subsection{Precipitation characterization}

The precipitation state was studied combining TEM and SEM techniques in both the as-received state and in selected heat-treated states. All heat treatments were realized in horizontal radiative furnace on parallelepiped samples of approximate dimensions $3 \times 10 \times 10 \mathrm{~mm}^{3}$ machined from the asreceived steel plate. In order to avoid excessive oxidation and decarburization, heat treatments were either performed under dynamic secondary vacuum or in primary vacuum sealed quartz tube. The samples are directly inserted in the furnace heated up to the target temperature. After heat treatment, the samples undergo water quenching.

Carbon extraction replicas were prepared from selected heat-treated samples. After polishing down to $1 \mu \mathrm{m}$ and nital (4\%) etching, a carbon layer was deposited on the etched sample using a SCD500 BALTEC carbon evaporator. Squares of approximately $2 \times 2 \mathrm{~mm}^{2}$ were drawn on the carbon-coated surface using a cutter blade. Samples were thereafter placed in a $4 \%$ nital solution until the sliced carbon films start delaminating from the sample surface. A carbon layer containing the precipitates was thus obtained. Afterwards, the carbon replicas were rinsed in three successive ethanol baths, and placed on nickel or copper grids.

Electron microscopy was performed on carbon replicas using a JEOL 2100 transmission electron microscope (TEM) operating at $200 \mathrm{kV}$. The precipitates were characterized in scanning transmission electron microscopy mode (STEM) - high angle annular dark field (HAADF) imaging. The STEM-HAADF technique provides a $Z$-contrast [28], which facilitates the observations: a large contrast appears between the carbon layer (dark) and the precipitates (bright). Other observations were performed on carbon replicas using a ZEISS Supra 55VP Scanning Electron Microscope with a field emission electron gun (FEG). Using backscattered electrons (BSE) mode, a chemical contrast was also obtained. Due to the chemical contrast obtained with both techniques, it was possible to directly distinguish precipitates containing different chemical species. Using FIJI [26], an image analysis procedure was developed to determine the precipitates sizes. The projected surface of precipitates $A_{P}$ was determined and an equivalent radius was calculated:

$$
r=\sqrt{\frac{A_{P}}{\pi}}
$$


Both TEM and SEM were equipped with Oxford energy-dispersive X-ray (EDX) analysers with silicon drift detector (SDD). EDX measurements were employed to determine the relative contents of the metallic species such as $\mathrm{Ti}, \mathrm{Nb}$ and $\mathrm{S}$. Lighter elements such as $\mathrm{C}$ and $\mathrm{N}$ cannot be correctly quantified by EDX. Moreover, carbon quantification was hindered by the presence of the carbon layer of the replicas. However, nitrogen can be detected if present in the precipitates.

Finally, the crystallographic nature of the precipitates was investigated using selected area electron diffraction (SAED) on a JEOL 2010F TEM microscope operating at $200 \mathrm{kV}$. The composition of each precipitate analysed by SAED was checked by EDX measurements. The crystallography data used for indexing the SAED patterns are extracted from [29]. $\mathrm{Ti}_{4} \mathrm{C}_{2} \mathrm{~S}_{2}$ precipitates present an hexagonal structure of space group $\mathrm{P} 6_{3} / \mathrm{mmc}$ with $a=b=$ $0.3210 \mathrm{~nm}$ and $c=1.120 \mathrm{~nm}$. TiN, TiC and $\mathrm{NbC}$ all share the same face-centered cubic (fcc) structure of space group $\operatorname{Fm} \overline{3} \mathrm{~m}$ with respectively $a=$ $0.4235 \mathrm{~nm}, a=0.4319 \mathrm{~nm}$, and $a=0.4469 \mathrm{~nm}$.

\section{Experimental results}

\subsection{Austenite grain size measurements}

Figure 1 displays optical micrographs from selected heat treatments showing prior austenite grain sizes (PAGS) revealed by the thermal etching method. Most of these micrographs allow an relatively accurate tracking of the austenite grain boundaries, which gives reliable PAGS. For the lower temperatures $\left(950{ }^{\circ} \mathrm{C}\right.$ and $\left.1000{ }^{\circ} \mathrm{C}\right)$, thermal etching was less effective and PAGS determination was more difficult. Figure 2 shows the PAGS revealed by a Béchet-Beaujard etching for the $1250^{\circ} \mathrm{C}$ heat treatment. For all temperatures, some austenite grain boundaries were not revealed, leading to uncertainties, that were estimated to be $20 \%$.

Figure 3 shows the resulting average PAGS measurements after 10 minutes isothermal heat treatments at temperature ranging from $950{ }^{\circ} \mathrm{C}$ to $1250{ }^{\circ} \mathrm{C}$. As expected, raising temperature results in increasing PAGS. Up to $1050^{\circ} \mathrm{C}$, PAGS remains roughly constant, with values between 10 and $20 \mu \mathrm{m}$. Starting from $1100^{\circ} \mathrm{C}$, a substantial austenite grain growth occurs. At $1250^{\circ} \mathrm{C}$, coarse grains were obtained, with a final grain diameter around $400 \mu \mathrm{m}$.

\subsection{Precipitation state characterization}

\subsubsection{As-received steel}

Three types of precipitates were identified in the initial state, combining STEM-HAADF, EDX (Figure 4), bright field observations, and SAED (Figure $5)$ :

- The main population observed was composed of precipitates whose radii approximately range from a few tens of $\mathrm{nm}$ to $150 \mathrm{~nm}$. They exhibited various geometrical forms, but were mainly spherical and cuboidal (Figure 4a)). Their mean composition in heavy elements were determined by EDX in SEM and TEM. Approximately 80 at $\%$ of Ti and 20 at $\%$ of $\mathrm{Nb}$ were detected. EDX measurements in SEM and TEM gave similar values (see Figure 7 a)). The indexation of SAED patterns are coherent with a fcc structure of space group 
a) $\quad 10 \min -1000^{\circ} \mathrm{C}$

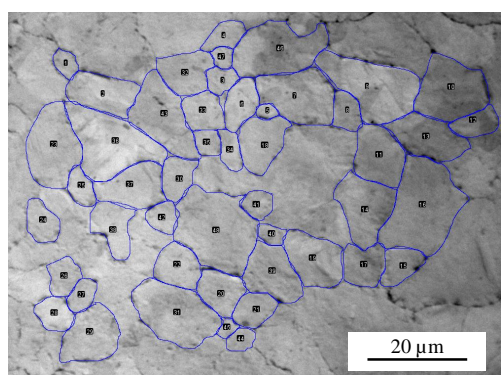

b) $\quad 10 \min -1100^{\circ} \mathrm{C}$

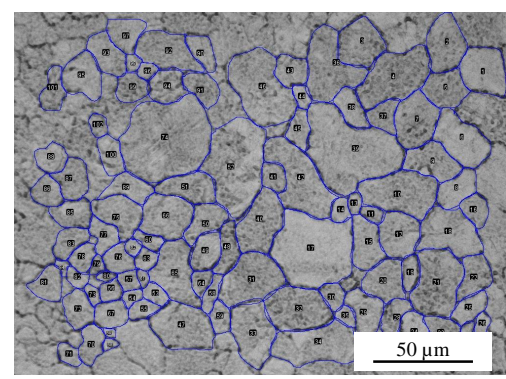

c) $\quad 10 \min -1200^{\circ} \mathrm{C}$

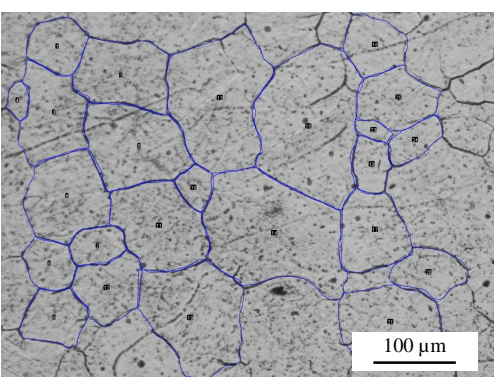

Figure 1: Optical micrographs showing PAGS revealed by thermal etching for 10 min holding treatments at $1000^{\circ} \mathrm{C}, 1100^{\circ} \mathrm{C}$ and $1200{ }^{\circ} \mathrm{C}$. The manual detouring used to calculate the the equivalent area diameter is shown in blue.

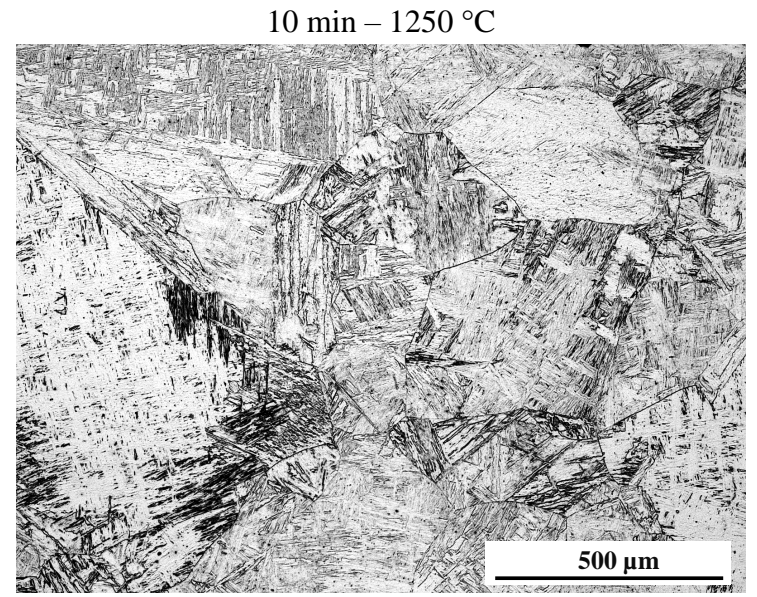

Figure 2: Optical micrograph showing PAGS revealed by Bechet-Beaujard etching after a 10 min holding treatment at $1250^{\circ} \mathrm{C}$.

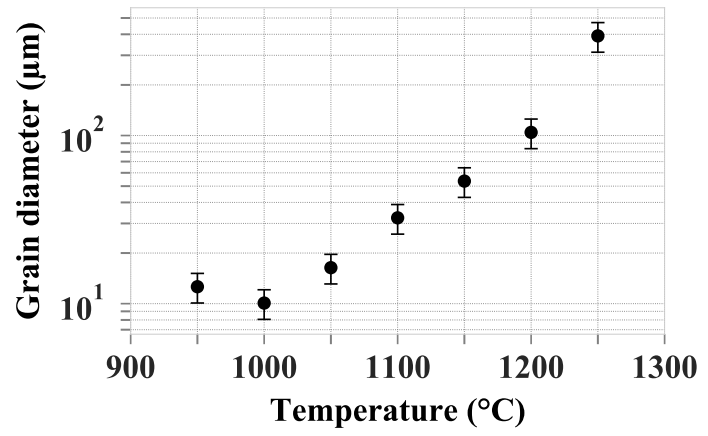

Figure 3: Evolution of PAGS for 10 minutes heat treatments at temperatures ranging from $950^{\circ} \mathrm{C}$ to $1250^{\circ} \mathrm{C}$
Fm $\overline{3} \mathrm{~m}$, like $\mathrm{TiC}$ and $\mathrm{NbC}$ (Figure $5 \mathrm{a})$ ). Although no peak of nitrogen emerge from the EDX spectra acquired from these precipitates, it is not possible to exclude the presence of $\mathrm{N}$ in quantities below the detection level. As a first approximation, it can be stated that these precipitates are mixed titanium-niobium carbides $(\mathrm{Ti}, \mathrm{Nb}) \mathrm{C}$.

- Some precipitates presenting larger sizes and mainly containing Ti and S were found. Small amounts of $\mathrm{Nb}$ were also detected in these precipitates. SAED patterns can be indexed with a hexagonal structure of space group $\mathrm{P}_{3} / \mathrm{mmc}$ (Figure $5 \mathrm{~b}$ )). Their mean EDX composition was determined (Figure $7 \mathrm{~b}$ )). SEM and TEM measurements were once again similar. The composition is compatible with $\mathrm{Ti}_{4} \mathrm{C}_{2} \mathrm{~S}_{2}$ ( $\mathrm{Ti}$ $\angle \mathrm{S} \approx 2$ ), leaving no doubt on the nature of this population.

- Finally, another population of very large cuboidal precipitates in which $\mathrm{Ti}$ and $\mathrm{N}$ were detected by EDX was also identified. They present a fcc structure of space group Fm $\overline{3} \mathrm{~m}$ 

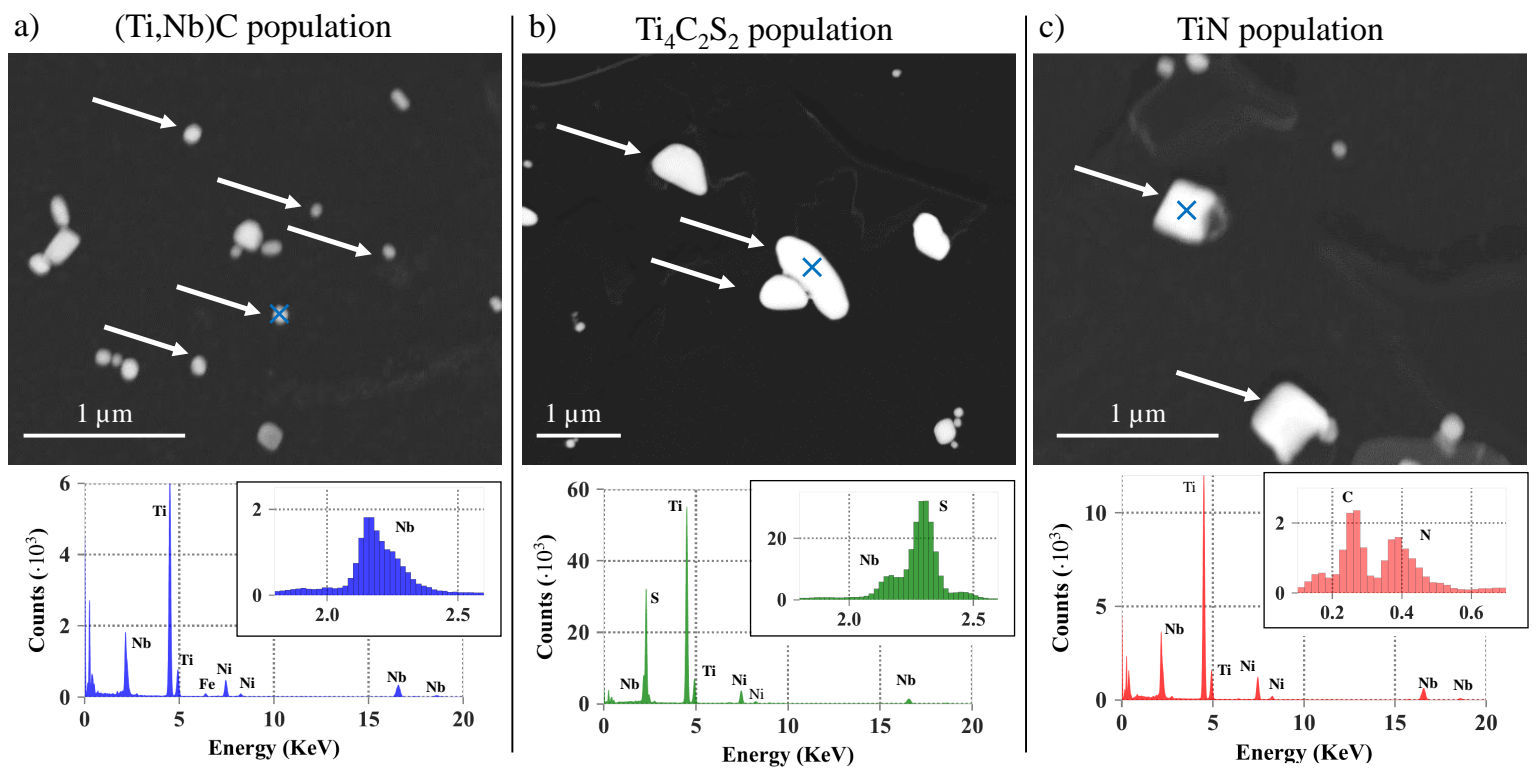

Figure 4: STEM-HAADF observation of the 3 populations of precipitates found in as-received steel, with associated EDX spectra. The Ni lines appearing in the spectra correspond to the grid holding the carbon replica. The blue crosses indicate the precipitates on which EDX was performed.

(Figure $5 \mathrm{c})$ ), like titanium nitride. These cuboids were then assumed to be TiN.

The titanium-niobium carbides $(\mathrm{Ti}, \mathrm{Nb}) \mathrm{C}$ were the most frequently observed precipitates, and also the smaller ones. Therefore, they are likely to be the one governing austenite grain growth during soaking at high temperature. Using the analysis routine developed on FIJI, the particle size distribution was determined from a series of images taken randomly at the same magnification in both SEM (BSE mode) and TEM (STEM-HAADF mode). The resulting precipitate size distributions are shown in figure 6. Log-normal laws accurately fit experimental size distributions for both SEM and TEM. The mean precipitates radius are equal $(56 \pm 5 \mathrm{~nm}$ for BSE and $58 \pm 5 \mathrm{~nm}$ for STEMHAADF). However the size distribution determined by SEM is slightly larger than the TEM one, which could be explained by the lower precision of SEM observations.

\subsubsection{Heat-treated samples}

In order to investigate the stability of the different types of observed precipitates, three isothermally heat treated states were investigated: $1050{ }^{\circ} \mathrm{C}, 1200^{\circ} \mathrm{C}$, and $1280^{\circ} \mathrm{C}$. After $240 \mathrm{~min}$ at $1050{ }^{\circ} \mathrm{C}$, and $30 \mathrm{~min}$ at $1200^{\circ} \mathrm{C}$, the three types of precipitates found in the initial state were still present. The EDX composition determined in SEM on $(\mathrm{Ti}, \mathrm{Nb}) \mathrm{C}$ and $\mathrm{Ti}_{4} \mathrm{C}_{2} \mathrm{~S}_{2}$ precipitates at $1200{ }^{\circ} \mathrm{C}$ are very close to the ones determined on those two types of precipitates in the initial state (see Figure 8). After 30 minutes at $1280^{\circ} \mathrm{C}$, only TiN precipitates were found on carbon replicas. There was no trace of $(\mathrm{Ti}, \mathrm{Nb}) \mathrm{C}$ nor $\mathrm{Ti}_{4} \mathrm{C}_{2} \mathrm{~S}_{2}$ at this tempera- 
a) $\quad(\mathrm{Ti}, \mathrm{Nb}) \mathrm{C}$ population
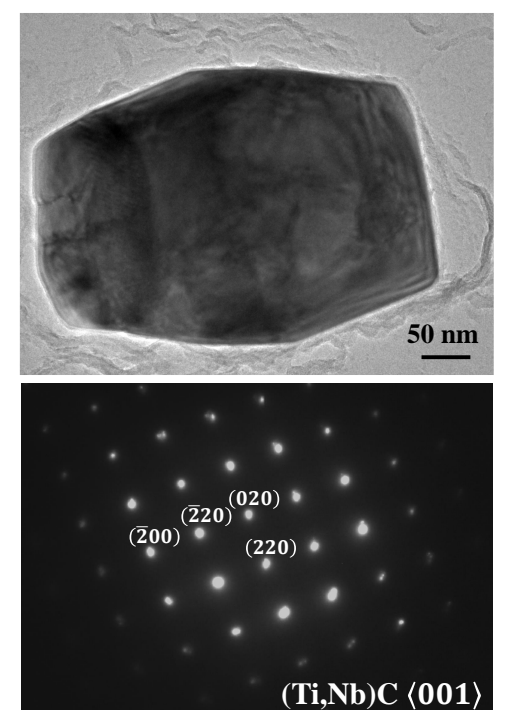

b)

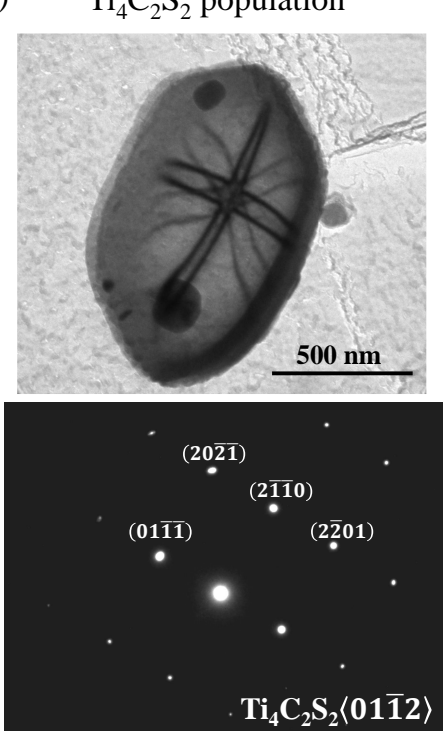

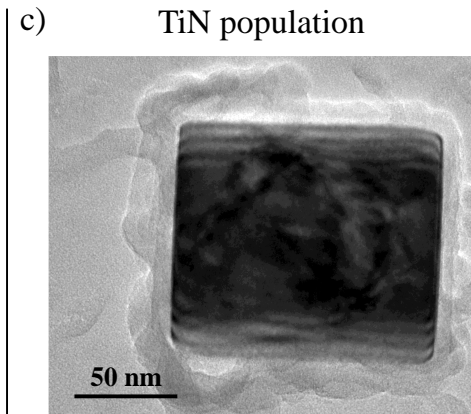

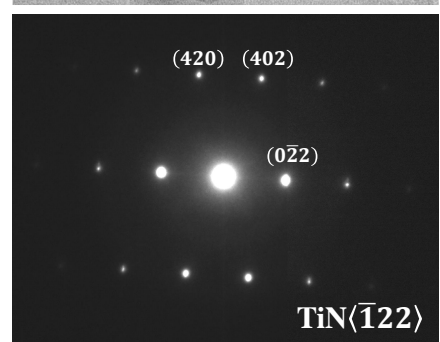

Figure 5: Bright field TEM observation of the 3 populations of precipitates found in as-received steel, with associated Selected area diffraction patterns.

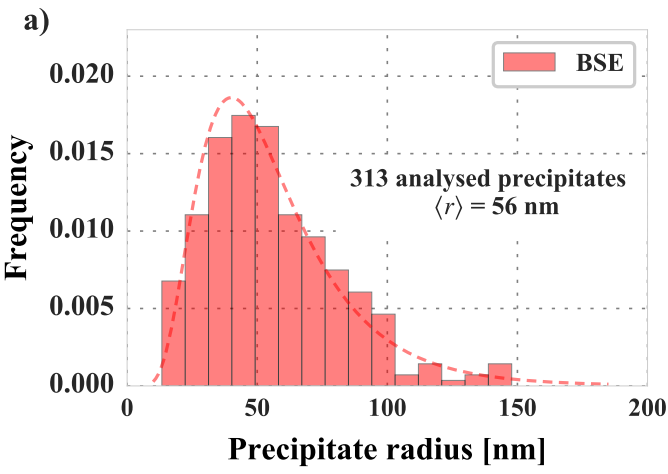

b)

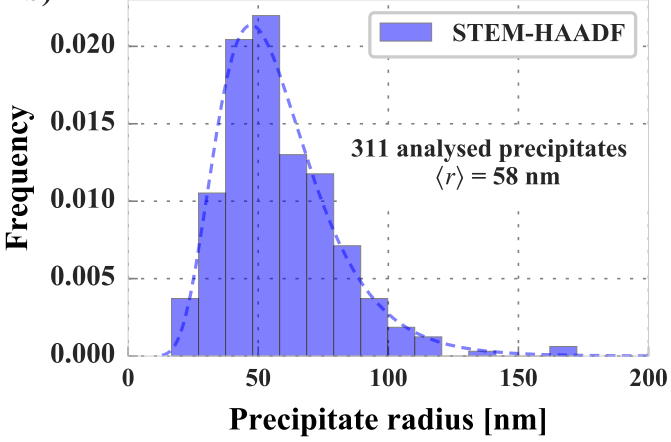

Figure 6: Initial distribution of $(\mathrm{Ti}, \mathrm{Nb}) \mathrm{C}$ precipitates characterized by MEB-BSE and STEM-HAADF
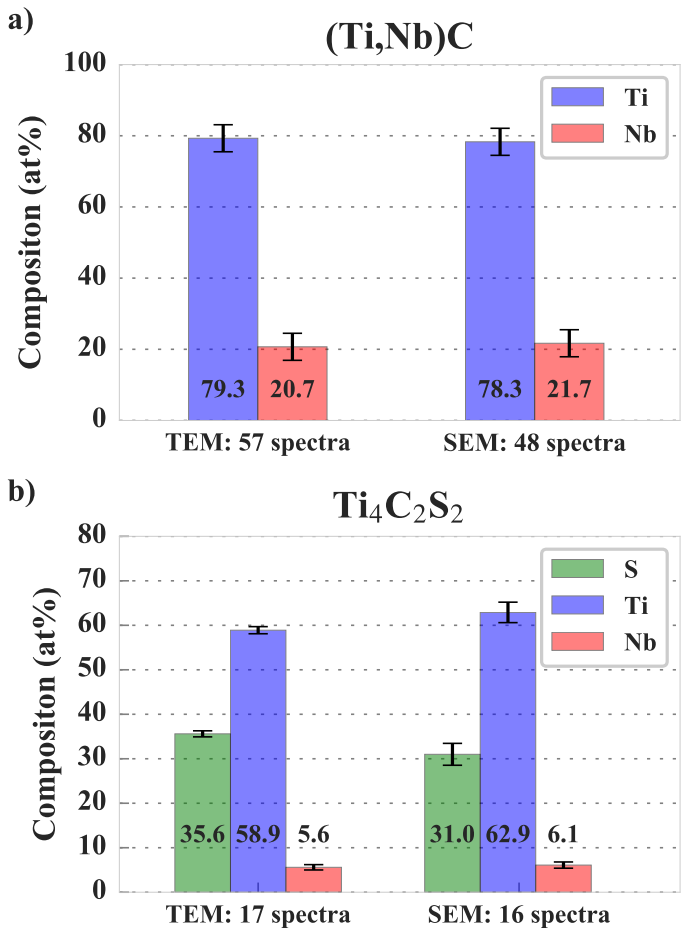

Figure 7: Mean composition of a) (Ti,Nb)C and b) $\mathrm{Ti}_{4} \mathrm{C}_{2} \mathrm{~S}_{2}$ precipitates determined by EDX in TEM and SEM. 


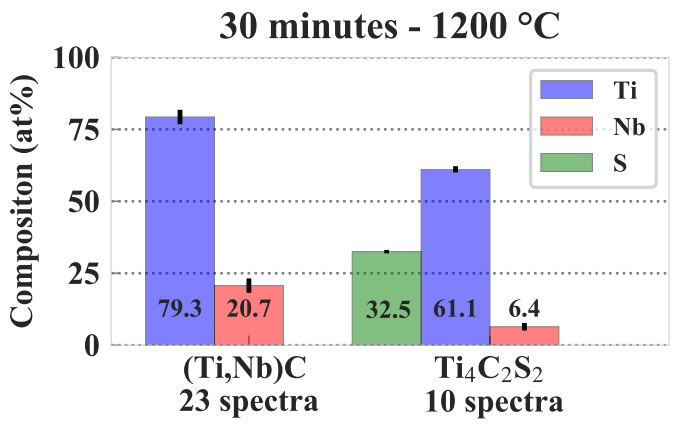

Figure 8: Mean composition of $(\mathrm{Ti}, \mathrm{Nb}) \mathrm{C}$ and $\mathrm{Ti}_{4} \mathrm{C}_{2} \mathrm{~S}_{2}$ found after $30 \mathrm{~min}$ at $1200^{\circ} \mathrm{C}$ determined by EDX in SEM.

ture, showing that these two populations of precipitates are no longer stable and completely dissolved at $1280^{\circ} \mathrm{C}$.

Additionally, the mean radius of $(\mathrm{Ti}, \mathrm{Nb}) \mathrm{C}$ was measured after $240 \mathrm{~min}$ at $1050^{\circ} \mathrm{C}$, and $30 \mathrm{~min}$ at $1200^{\circ} \mathrm{C}$. Mean radii of $66 \pm 5 \mathrm{~nm}$ and $67 \pm 5 \mathrm{~nm}$ were respectively found.

\section{Model}

\subsection{Equilibrium calculations}

Modelling the evolution of precipitation state with time and temperature requires having a correct estimation of the stability domain of phases. In particular, the solubility product of the precipitates is an essential parameter. In the present case, the key population is $(\mathrm{Ti}, \mathrm{Nb}) \mathrm{C}$, whose sizes makes it effective for grain boundary pinning. Two types of calculations were performed and compared to estimate the stability of the observed precipitates.

First calculations were performed in austenite domain using the commercial ThermoCalc software [30] with TCFE8 Steels/Fe-alloys database [31]. The steel composition determined by ICP-MS (Table 1) was used as input.

According to TCFE8 database, manganese sulfide $\mathrm{MnS}$ is found to be more stable than titanium carbo-sulphide $\mathrm{Ti}_{4} \mathrm{C}_{2} \mathrm{~S}_{2}$. Since no $\mathrm{MnS}$ were experimentally observed, equilibrium calculations were performed ruling out $\mathrm{MnS}$ and all related phases (dormant phases), in order to better describe the actual microstructure. Figure 9 a) shows the results of these calculations. Three populations are present in austenite: $(\mathrm{Ti}, \mathrm{Nb}) \mathrm{C}, \mathrm{Ti}(\mathrm{C}, \mathrm{N})$ and $\mathrm{Ti}_{4} \mathrm{C}_{2} \mathrm{~S}_{2}$. The stability of $(\mathrm{Ti}, \mathrm{Nb}) \mathrm{C}$ phase goes up to approximately $1200^{\circ} \mathrm{C}$ and the maximum volume fraction remains below 0.001 . The volume fraction of $\mathrm{Ti}(\mathrm{C}, \mathrm{N})$ population stays roughly constant around 0.001 and start decreasing once the $(\mathrm{Ti}, \mathrm{Nb}) \mathrm{C}$ population is not stable anymore. $\mathrm{Ti}_{4} \mathrm{C}_{2} \mathrm{~S}_{2}$ precipitates are stable over the entire temperature range studied, with a volume fraction of approximately 0.0002

These first full-equilibrium calculations are not in agreement with experiments (see section 2.3) because:

- The stability of $\mathrm{Ti}_{4} \mathrm{C}_{2} \mathrm{~S}_{2}$ is overestimated since it was here experimentally established that these precipitates were no longer stable at $1280^{\circ} \mathrm{C}$.

- The calculations also predict a complete dissolution of the $(\mathrm{Ti}, \mathrm{Nb}) \mathrm{C}$ population around $1200^{\circ} \mathrm{C}$ whereas an intensive population of these precipitates were found on carbon replicas after a heat treatment of 30 minutes at this temperature.

- Furthermore, the calculated composition of 

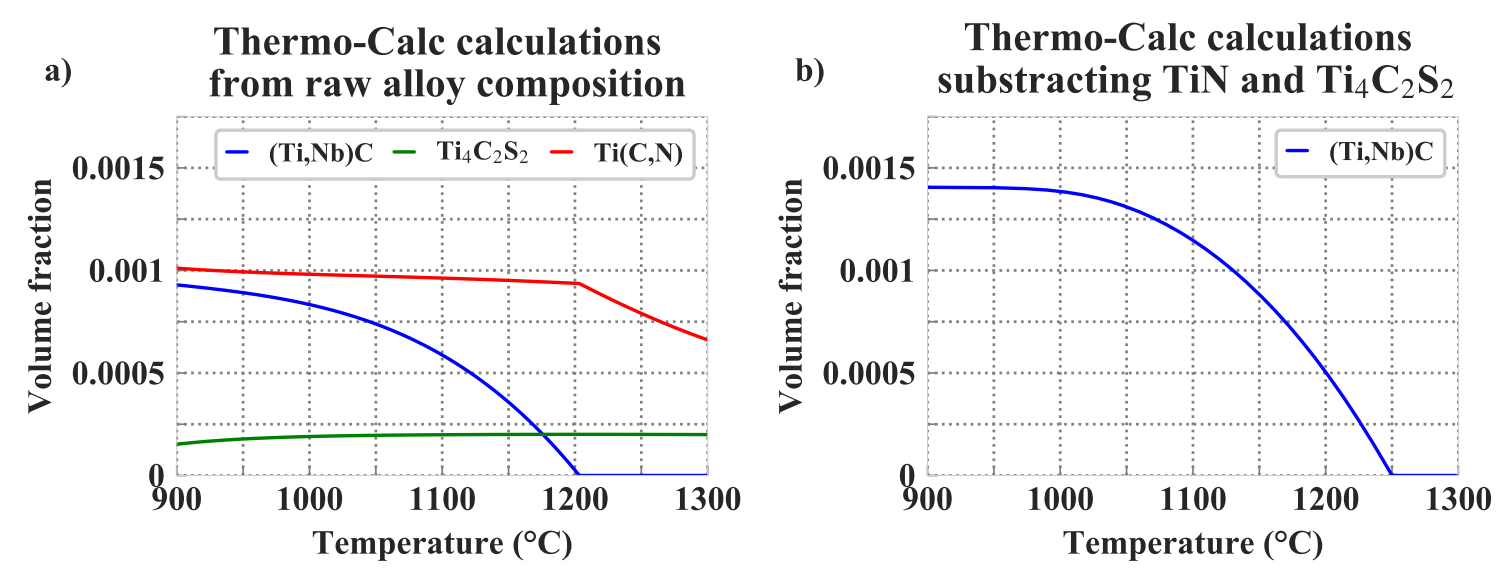

Figure 9: Equilibrium volume fractions of precipitates a) resulting from Thermo-Calc calculations with TCFE8 database for all precipitates and b) assuming that all $\mathrm{N}$ and $\mathrm{S}$ react to form respectively TiN and $\mathrm{Ti}_{4} \mathrm{C}_{2} \mathrm{~S}_{2}$ and using Thermo-Calc for calculating the solubility product of $(\mathrm{Ti}, \mathrm{Nb}) \mathrm{C}$.

( $\mathrm{Ti}, \mathrm{Nb}) \mathrm{C}$ gives approximately $57 \%$ of titanium and $43 \%$ of niobium. This composition is quite different from that obtained experimentally by EDX on this population of precipitates (see Figures 7 and 8).

The apparent disagreement between fullequilibrium thermodynamics calculations and experimental results can be explained by the fact that full equilibrium is not reached. The alloy's thermal history starting from high temperatures has therefore to be accounted for.

As a consequence, the stability of the precipitates was reconsidered using several assumptions. TiN are known to be amongst the most stable precipitates [5]. They form at the earliest stages of the casting process [32], even from liquid state. Therefore, here it was assumed that the total amount of $\mathrm{N}$ reacted with the corresponding amount of $\mathrm{Ti}$ to form a stoichiometric TiN population. All $\mathrm{N}$ as well as the corresponding amount of $\mathrm{Ti}$ was removed from the input composition.

Since $\mathrm{Ti}_{4} \mathrm{C}_{2} \mathrm{~S}_{2}$ are also known to be very stable in austenite [33], it was assumed that they undergo limited dissolution over the temperature range of interest (i.e. between $950^{\circ} \mathrm{C}$ and $1250^{\circ} \mathrm{C}$ ). As a first approximation, all $\mathrm{S}$ and the corresponding $\mathrm{Ti}$ and $\mathrm{C}$ were also removed from input composition. The new input composition obtained is listed in Table 2 .

TCFE8 database [31] gave a relatively constant composition of $(\mathrm{Ti}, \mathrm{Nb}) \mathrm{C}$ over the studied temperature range: $\left(\mathrm{Ti}_{0.69 \pm 0.05}, \mathrm{Nb}_{0.31 \pm 0.05}\right) \mathrm{C}_{0.96 \pm 0.02}$. Thus, a simplified average composition between $A_{e 3}$ and the dissolution temperature was taken. It was also assumed that the number of metallic (Ti and $\mathrm{Nb}$ ) atoms was equal to the number of carbon atoms (no vacancy in precipitates), giving the following precipitate composition: $\mathrm{Ti}_{0.7} \mathrm{Nb}_{0.3} \mathrm{C}$.

Using the evolution of austenite composition with temperature, the solubility product was evaluated 


\begin{tabular}{ccccccc}
\hline Element & $\mathrm{C}$ & $\mathrm{Mn}$ & $\mathrm{Ti}$ & $\mathrm{Nb}$ & $\mathrm{S}$ & $\mathrm{N}$ \\
\hline Initial (at\%) & 0.2861 & 1.927 & 0.0984 & 0.0233 & 0.0052 & 0.0237 \\
\hline Subtracting TiN and $\mathbf{T i}_{4} \mathbf{C}_{2} \mathbf{S}_{2}(\mathbf{a t \% )}$ & 0.2757 & 1.927 & 0.0643 & 0.0233 & 0 & 0 \\
\hline
\end{tabular}

Table 2: Calculation of the input composition (at\%) for Thermo-Calc calculations of (Ti,Nb)C stability assuming that all $\mathrm{N}$ and $\mathrm{S}$ react with $\mathrm{Ti}$ to form $\mathrm{TiN}$ and $\mathrm{Ti}_{4} \mathrm{C}_{2} \mathrm{~S}_{2}$, respectively.

at each temperature using:

$$
K_{S}=\left(X_{\mathrm{Ti}}^{e q}\right)^{0.7}\left(X_{\mathrm{Nb}}^{e q}\right)^{0.3} X_{\mathrm{C}}^{e q}
$$

with $X_{i}^{e q}$ the atomic fraction of element $i$ in austenite. Then by linearly fitting the evolution of $\log _{10} K_{S}$ with $1 / T$, the following expression was taken for the solubility product of $(\mathrm{Ti}, \mathrm{Nb}) \mathrm{C}$ :

$$
\log _{10} K_{S}=-\frac{9626 K}{T}+0.44
$$

Figure 10 compares the obtained solubility product for $\mathrm{Ti}_{0.7} \mathrm{Nb}_{0.3} \mathrm{C}$ with values of the literature. This precipitate is found more stable than NbC and TiC, probably due to entropy effects.

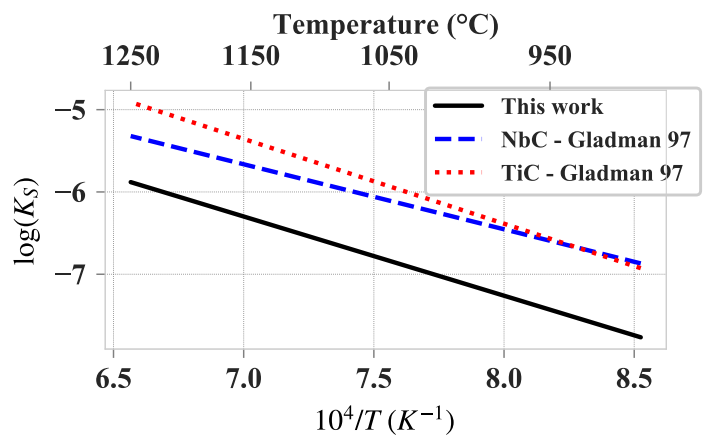

Figure 10: Comparison of the solubility product used (equation 4) and reference solubility products of $\mathrm{TiC}$ and $\mathrm{NbC}$ from Gladman [5].

Figure 9 b) shows the stability domain of ( $\mathrm{Ti}, \mathrm{Nb}) \mathrm{C}$ using the aforementioned solubility product, considering complete precipitation of TiN and $\mathrm{Ti}_{4} \mathrm{C}_{2} \mathrm{~S}_{2}$ over the whole range of temperature. The resulting stability of $(\mathrm{Ti}, \mathrm{Nb}) \mathrm{C}$ significantly differs from the first calculations performed with the raw alloy composition. Their volume fraction is also higher (above 0.0014 instead of less than 0.001). (Ti,Nb)C completely dissolve around $1250^{\circ} \mathrm{C}$ instead of $1200^{\circ} \mathrm{C}$. Thus, assuming complete precipitation of $\mathrm{TiN}$ and $\mathrm{Ti}_{4} \mathrm{C}_{2} \mathrm{~S}_{2}$ leads to a stability domain of $(\mathrm{Ti}, \mathrm{Nb}) \mathrm{C}$ in better agreement with experimental observations (Figure $9 \mathrm{~b})$ ).

\subsection{Grain growth model}

A Zener-type model accounting for the competition between driving pressure for grain growth $P_{D}$ and precipitate pinning pressure $P_{P}$ was used. Under the influence of pinning precipitates, the grain diameter $D$ growth rate can be expressed by:

$$
\frac{d D}{d t}=\left\{\begin{array}{ccc}
M\left(P_{D}-P_{P}\right) & \text { if } & P_{D}-P_{P}>0 \\
0 & \text { if } & P_{D}-P_{P}<0
\end{array}\right.
$$

$M$ is the interface boundary mobility, described by an Arrhenius law:

$$
M=M_{0} \exp \left(\frac{-Q_{G G}}{R_{g} T}\right)
$$

Here $M_{0}$ is a pre-exponential factor, $R_{g}$ is the gas constant and $Q_{G G}$ is the activation energy for grain boundary mobility.

The driving pressure for grain growth is given by:

$$
P_{D}=\beta \frac{\gamma}{D}
$$


Where $\beta$ is a coefficient, $\gamma$ is the austenite interface energy and $D$ is the mean grain diameter. Zener [34], originally considered that $\beta=4$. This value is actually overestimated as several experimental and modelling work seem to prove that the correct expression of the driving pressure for grain growth in polycristalline materials is four times lower [35-38]. Thus, $\beta$ is taken equal to 1 in the present work.

Numerous expressions for pinning pressure can be found in literature (see the reviews by Manohar et al. [39], and by Huang and Logé [40]). The pinning pressure $P_{P}$ is generally calculated with the following expression:

$$
P_{P}=\alpha \gamma \frac{f}{\langle r\rangle}
$$

Where $\alpha$ is a coefficient, $f$ is the mean volume fraction of precipitates, and $\langle r\rangle$ is the mean precipitate radius.

Among these expressions, the one given by Zener in 1948 [34], and the one given by Rios in 1987 [41] are particularly relevant, and somehow define a lower and an upper bound for the pinning pressure. Zener [34] considered that grain boundaries bypass precipitates following a pass-through mechanism and obtained $\alpha=3 / 2$. Considering that grain boundaries bend round and envelope pinning precipitate (enveloping mechanism), Rios [41] derived a pinning pressure two times higher than Zener's: $\alpha=3$.

Additionally, the present model took into account the effect of several classes of precipitates with different sizes instead of adopting a mean-radius approach. The expression for pinning pressure was thus modified as:

$$
P_{P}=\alpha \gamma \sum_{i} \frac{f_{i}}{r_{i}}
$$

where $i$ is a summation index representing all the present precipitates classes of different radius $r_{i}$ and having the volume fraction $f_{i}$.

\subsection{Precipitation model}

In this work, the software Preciso [42, 43] was used to follow the evolution of precipitation state during heat treatments. It is based on the classical nucleation, growth and coarsening theories, fully described in [20]. The precipitation state was characterized by the whole precipitate size distribution (Lagrange-like approach). Since only reversion experiments are to be modeled, only growth and coarsening equations are presented here (no nucleation).

\subsubsection{Growth and coarsening}

The diffusion of solute elements governs the growth of nucleated precipitates. The diffusion coefficient of an element $i$, noted $D_{i}$, follows an Arrhenius law $D_{i}^{0} \exp \left(-Q_{i} /\left(R_{g} T\right)\right) . \quad D_{i}^{0}$ is the preexponential factor, and $Q_{i}$ is the energy activation. The growth rate of a precipitate is given for element $i$ by:

$$
\frac{d r}{d t}=\frac{D_{i}}{r} \frac{X_{i}^{m}-X_{i}^{e q}(r)}{\alpha_{v} X_{i}^{P}-X_{i}^{e q}(r)}
$$

$\alpha_{v}=v_{a t}^{m} / v_{a t}^{p}$ is the ratio of matrix to precipitates atomic volumes, and $X_{i}^{P}(r)$ is the atomic fraction of element $i$ at the interface between matrix and a precipitate of radius $r$.

In fact, the presence of an interface between matrix and precipitates (i.e. the interface curvature) 
modifies the local equilibrium and atomic fractions at the interface (Gibbs-Thomson effect [44]). Thus, the concentrations of solute elements at the interface of a $\mathrm{Ti}_{x} \mathrm{Nb}_{y} \mathrm{C}_{z}$ precipitate are given by the solubility product modified by a factor traducing the effect of interface curvature:

$$
\begin{aligned}
X_{\mathrm{Ti}}^{e q}(r)^{x} X_{\mathrm{Nb}}^{e q}(r)^{y} X_{\mathrm{C}}^{e q}(r)^{z} \\
\quad=K_{S} \exp \left(\frac{2 \gamma_{P}(x+y+z) v_{a t}^{P}}{r k_{B} T}\right)
\end{aligned}
$$

Eqs. 11 and 12 provide a system of 4 equations ( 3 diffusion equations - Ti, Nb and C - plus solubility product) with 4 unknown $\left(d r / d t\right.$ and $\left.X_{i}^{e q}\right)$.

At each timestep, growth of all existing classes is performed using eqs. 11 and 12 . Consequently, precipitate coarsening (Ostwald ripening) is implicitly accounted for in this approach.

\subsubsection{Mass balance}

Finally, mass balance is performed to update the new solute content of all elements:

$$
X_{i}^{m}=\frac{X_{i}^{0}-\alpha_{v} f X_{i}^{P}}{1-\alpha_{v} f}
$$

where $X_{i}^{0}$ is the total amount of solute $i$.

\subsection{Coupling between precipitation and grain growth models}

Precipitation and grain growth models are coupled but run separately. The precipitation model was first run providing the precipitate size distributions at each time step in the form of a large output file. Then, in a second stage, this file is read and, at each time step, the pinning pressure is calculated and the grain growth equation (eq.6) is integrated.

\subsection{Model parameters}

The evolution of precipitation was modelled for several holding treatments and coupled with the grain growth model, with the aim of reproducing the results obtained in section 3.1. Only $(\mathrm{Ti}, \mathrm{Nb}) \mathrm{C}$ precipitates were considered in the precipitation model. As discussed in section 3.2, given their respective sizes, TiN and $\mathrm{Ti}_{4} \mathrm{C}_{2} \mathrm{~S}_{2}$ populations have a very limited pinning effect. The chemical composition of the matrix used in the precipitation model is given in Table 2 .

The precipitation model used the solubility product given in equation 5 . The diffusion coefficient of alloying elements were calculated from the MOBFE3 Steels/Fe-Alloys Mobility Database [46] (see Table 4). Precipitate/matrix interface energy was taken equal to $0.7 \mathrm{~J} \cdot \mathrm{m}^{-2}$, in agreement with Maalekian et al [17].

The initial distribution of $(\mathrm{Ti}, \mathrm{Nb}) \mathrm{C}$ precipitates experimentally determined by TEM (Figure 6 b)) served as an input for the precipitation model. The STEM-HAADF distribution was used because of the better precision and resolution of TEM measurements compared to SEM. Based on a lognormal fitting curve, a theoretical precipitate distribution of 100 classes was calculated. The following expression was used for the probability density function:

$$
f(r, \mu, \sigma)=\frac{1}{r \sigma \sqrt{2 \pi}} \exp \left(-\frac{(\ln (r / \mathrm{nm})-\mu)^{2}}{2 \sigma^{2}}\right)
$$

with $\mu=3.991$ and $\sigma=0.369$. The total number of precipitates was adjusted in order to give an initial volume fraction of $(\mathrm{Ti}, \mathrm{Nb}) \mathrm{C}$ of 0.0014 , which is 


\begin{tabular}{ccc}
\hline Parameter & Value & Source/Comment \\
\hline$M_{0}$ & $10^{4} \mathrm{~m}^{4} \mathrm{~J}^{-1} \mathrm{~s}^{-1}$ & Fit parameter. \\
\hline$Q_{G G}$ & $390 \mathrm{~kJ} / \mathrm{mol}$ & Uhm et al $[45]$. \\
\hline Initial austenite grain diameter & $10 \mu \mathrm{m}$ & Grain growth measurements. \\
\hline Austenite grain boundary energy & $0.5 \mathrm{~J} \cdot \mathrm{m}^{-2}$ & See equation 5. \\
\hline$(\mathrm{Ti}, \mathrm{Nb}) \mathrm{C}$ solubility product & $\log _{10} K_{S}=-9626 \mathrm{~K} / \mathrm{T}+0.44$ & Close to maximum. \\
\hline$(\mathrm{Ti}, \mathrm{Nb}) \mathrm{C}$ initial volume fraction & 0.0014 & STEM-HAADF (Figure 6 a)). \\
\hline$(\mathrm{Ti}, \mathrm{Nb}) \mathrm{C}$ initial distribution & $\mu=3.991 \mathrm{and} \sigma=0.369$ & Adjusted to fit (Ti,Nb)C growth.
\end{tabular}

Table 3: Modelling parameters used.

\begin{tabular}{ccc} 
Element & $D_{0}\left[\mathrm{~m}^{2} \cdot \mathrm{s}^{-1}\right]$ & $Q\left[\mathrm{~J} \cdot \mathrm{mol}^{-1}\right]$ \\
\hline $\mathrm{C}$ & $2.4 \times 10^{-5}$ & 147800 \\
\hline $\mathrm{Ti}$ & $1.5 \times 10^{-5}$ & 251000 \\
\hline $\mathrm{Nb}$ & $8.9 \times 10^{-5}$ & 266400
\end{tabular}

Table 4: Diffusion coefficient used in the precipitation model, calculated from the MOBFE3 mobility database of ThermoCalc.

close to the maximum precipitate volume fraction given by mass balance.

An initial austenite grain diameter of $10 \mu \mathrm{m}$ was assumed, based on the experimental results given in part 3.1. An austenite grain boundary energy of $0.5 \mathrm{~J} / \mathrm{m}^{2}$ was assumed. Concerning grain boundary mobility, Uhm et al [45] determined an expression of the activation energy by multiple regression analysis for steels containing $\mathrm{C}, \mathrm{Mn}, \mathrm{Ni}, \mathrm{Cr}, \mathrm{Mo}$ and $\mathrm{Si}$. Based on this study, a value of $390 \mathrm{~kJ} / \mathrm{mol}$ was used. The mobility factor $M_{0}$ is the only fitting parameter: it was taken equal to $10^{4} \mathrm{~m}^{4} \mathrm{~J}^{-1} \mathrm{~s}^{-1}$.

\section{Modelling Results}

\subsection{Precipitation}

Several reversion heat treatments were performed in the stability domain of $(\mathrm{Ti}, \mathrm{Nb}) \mathrm{C}$ in austenite. Figure 11 shows the main output results of the precipitation model. The volume fraction of $(\mathrm{Ti}, \mathrm{Nb}) \mathrm{C}$ rapidly decreases as a result of the dissolution process. Meanwhile, a slight diminution of the mean precipitate radius and a consequent decrease of the number density (i.e. the number of precipitates per cubic meter) are observed. After precipitate shrinkage, coarsening occurs, causing a decrease in precipitate number density, and an increase in mean radius, while volume fraction remains constant. Eventually, the volume fraction reaches the equilibrium value given by the solubility product at $1200{ }^{\circ} \mathrm{C}$.

Microalloying elements are released in solid solution in the austenite phase due to the dissolution of precipitates. The observations made on number density and mean radius of the $(\mathrm{Ti}, \mathrm{Nb}) \mathrm{C}$ population can also be performed looking at the evolution 
a)

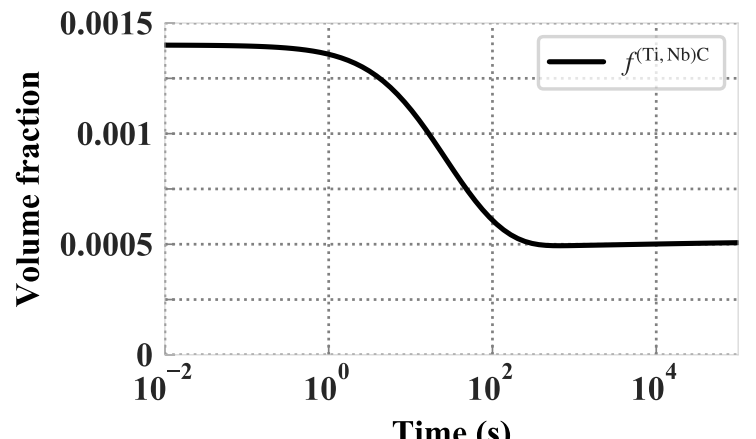

c)

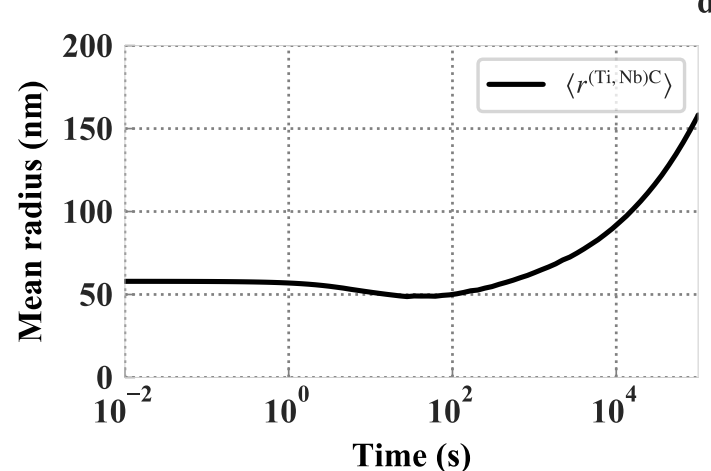

b)

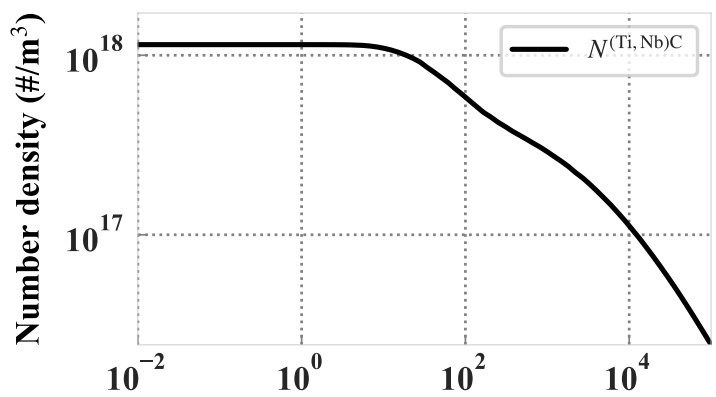

Time (s)

d)

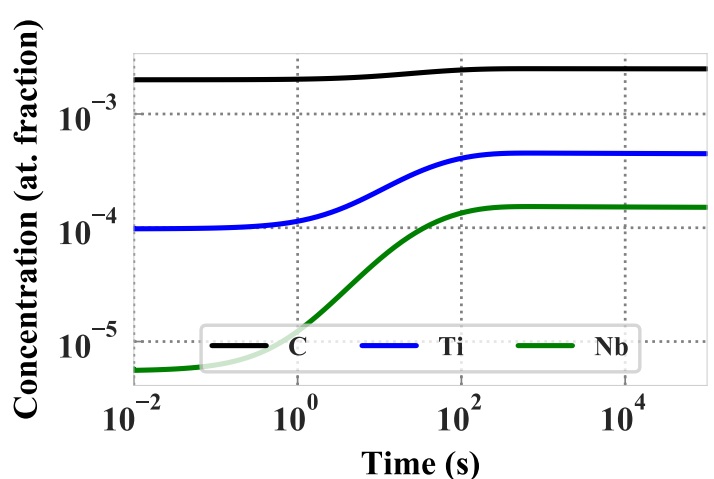

Figure 11: Effect of a simulated $1200{ }^{\circ} \mathrm{C}$ heat treatment on a) volume fraction, b) number density and c) mean (Ti,Nb)C radius and d) austenite solute content of $\mathrm{C}, \mathrm{Ti}$ and $\mathrm{Nb}$.

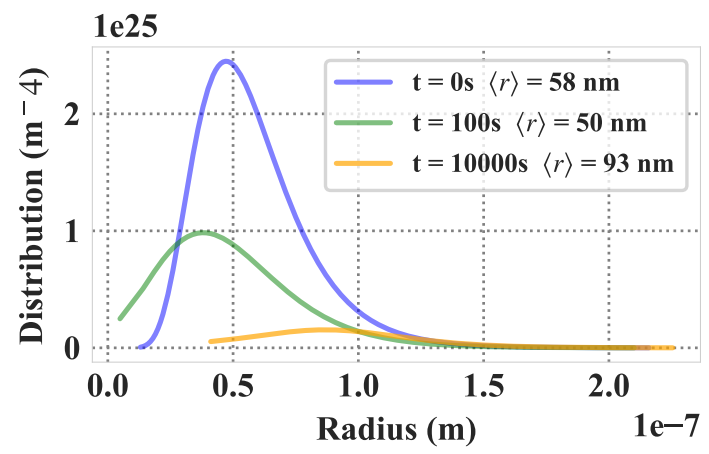

Figure 12: Evolution of the precipitate size distribution of $(\mathrm{Ti}, \mathrm{Nb}) \mathrm{C}$ with time for a $1200^{\circ} \mathrm{C}$ isothermal holding.

of the precipitate size distribution with time, which is shown in Figure 12.

Figure 13 shows the simulated evolution of the volume fraction and mean precipitate radius of the $(\mathrm{Ti}, \mathrm{Nb}) \mathrm{C}$ population for several reversion heat treatments ranging from $1000^{\circ} \mathrm{C}$ to $1250^{\circ} \mathrm{C}$. Experimentally determined mean radii are also plotted. The kinetics of precipitate dissolution is temperature-dependent: higher temperature leads to faster dissolution. At $1250{ }^{\circ} \mathrm{C}$, the precipitates are finally completely dissolved. The kinetics of precipitate growth is also temperature-dependent: as expected, higher temperature leads to faster growth kinetics.

\subsection{Austenite grain growth}

The pinning effect of $(\mathrm{Ti}, \mathrm{Nb}) \mathrm{C}$ particles is largely affected during heat treatments due to the massive 
a) 0.0015

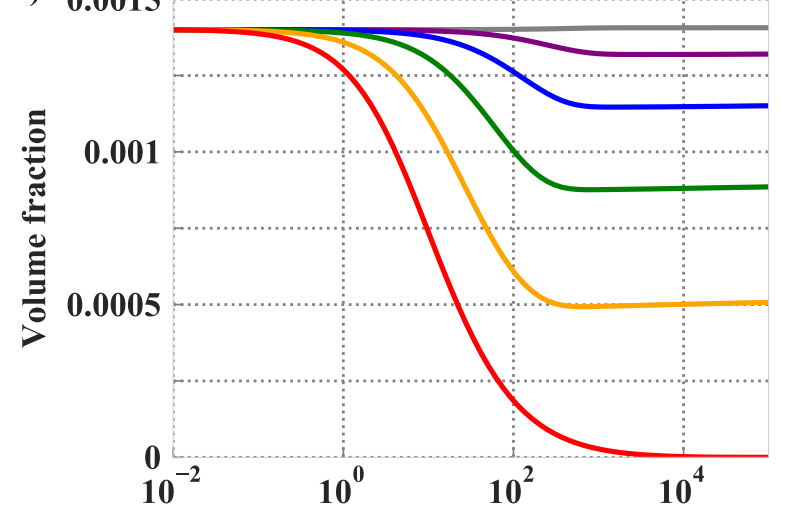

b) 150

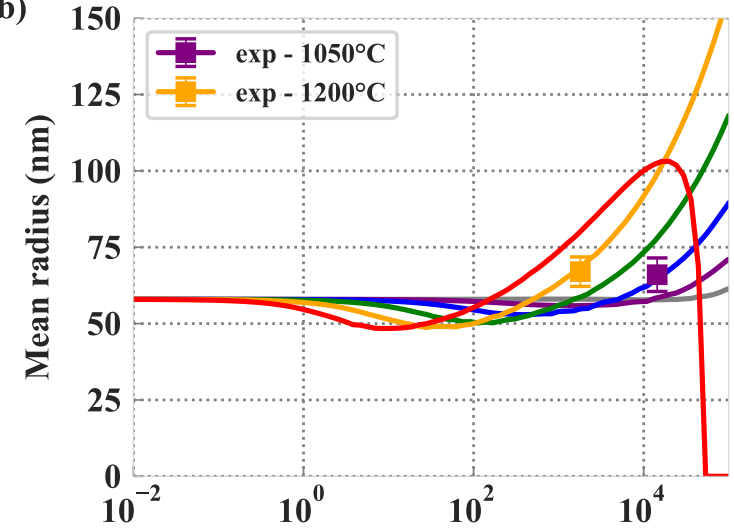

Time (s)

$\longrightarrow 1000^{\circ} \mathrm{C}-1050^{\circ} \mathrm{C}-1100^{\circ} \mathrm{C}-1150^{\circ} \mathrm{C}-1200^{\circ} \mathrm{C}-1250^{\circ} \mathrm{C}$

Figure 13: Evolution of the a) volume fraction and b) mean precipitate radius of ( $\mathrm{Ti}, \mathrm{Nb}) \mathrm{C}$ for several isothermal heat treatments.

evolution of the precipitation state. Figure 14 illustrates the effect of the evolution of the precipitation state on pinning pressure at $1200^{\circ} \mathrm{C}$. On this figure, the pinning pressure was calculated according to $\operatorname{Rios}(\alpha=3)$. The effect of the $\alpha$ coefficient was discussed in section 6. Figure 14 a) shows the evolution of the pinning ratio (defined as either from averaged values $f /\langle r\rangle$, or from the actual size distribution $\left(\sum_{i} f_{i} / r_{i}\right)$. It must be noted that taking averaged parameters $f$ and $\langle r\rangle$ leads to an overestimation of the initial pinning pressure of more than $31 \%$.

Figure $14 \mathrm{~b}$ ) shows the time evolution of driving and pinning pressures. Pinning pressure exerted by (Ti,Nb)C particles decreases during holding, as the precipitate number density decreases. The difference between the driving pressure for grain growth and the pinning pressure on grain boundaries is positive, leading thus to grain growth (according to equation 6) as illustrated in figure $14 \mathrm{c}$ )). As the austenite grain diameter increases, the driving pres- sure decreases, until both pressures become equal.

\section{Discussion}

Almost all modelling parameters were extracted from literature and/or thermodynamic databases. Two parameters were unknown, however: the initial volume fraction of $(\mathrm{Ti}, \mathrm{Nb}) \mathrm{C}$ and the precipitate/matrix interface energy. It was chosen to set the initial volume fraction at 0.0014 , which is close to the maximum volume fraction. Since the initial state was obtained through hot rolling and air cooling, there is a high probability that the precipitate volume fraction is maximum. The precipitate/matrix interface energy was set to $0.7 \mathrm{~J} \cdot \mathrm{m}^{-2}$ by fitting the experimental data on precipitate growth. This value is close to the one calculated by [17] for $\mathrm{NbC}$ from a nearest neighbour broken bond model $\left(0.66 \mathrm{~J} \cdot \mathrm{m}^{-2}\right)$. This parameter has only little influence on reversion kinetics, since nucleation does not take place during reversion. 

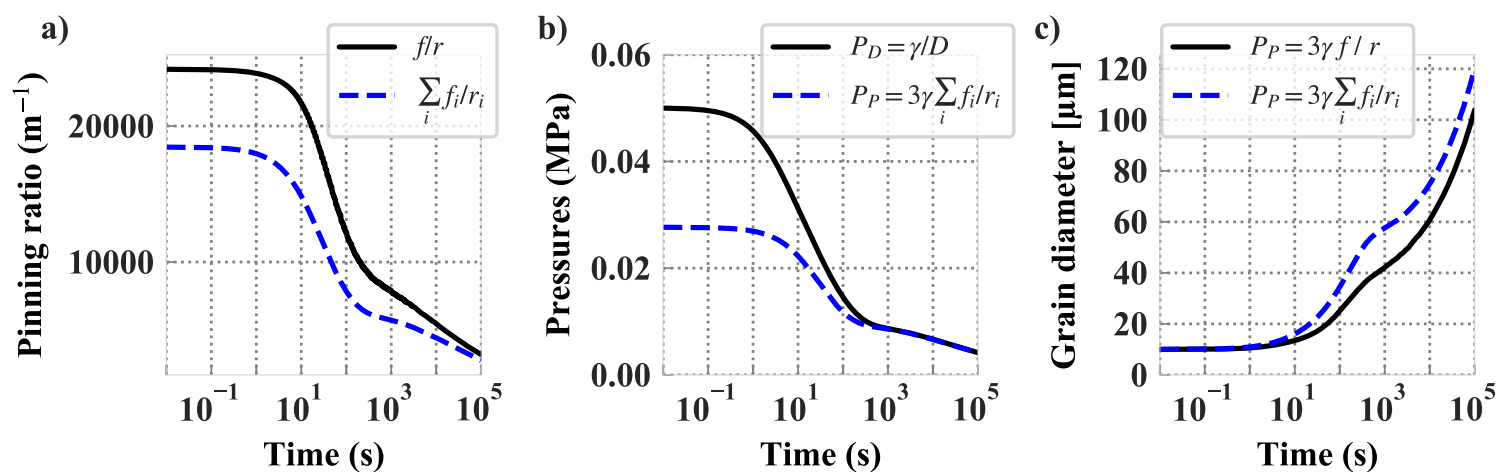

Figure 14: Evolution of a) pinning parameter, b) driving and pinning pressure induced by (Ti,Nb)C and c) austenite grain diameter during a thermal treatment at $1200^{\circ} \mathrm{C}$, considering the expression of pinning pressure given by Rios [41].

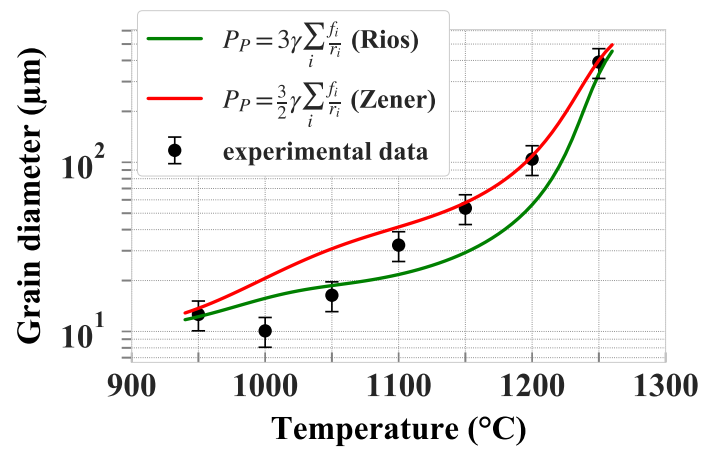

Figure 15: Predicted and experimentally determined austenite grain diameter for 10 minutes isothermal heat treatments.

Figure 15 compares experimental (see section 3.1) and predicted grain sizes for 10 minutes heat treatments at temperatures ranging from $950{ }^{\circ} \mathrm{C}$ to $1250^{\circ} \mathrm{C}$. The experimental data globally lies between the values predicted using Zener $(\alpha=3 / 2)$ and Rios $(\alpha=3)$ approaches (see section 4.2$)$.

Note that the whole precipitate size distribution was used to evaluate the pinning pressure, whereas many other authors used averaged volume fraction and radii $[14,16,17,47]$. It has been shown (Figure 14 a)) that using averaged parameters leads to an overestimation of the pinning pressure. Figure 14 c) compares the austenite grain growth kinetics at $1200^{\circ} \mathrm{C}$ obtained using averaged parameters or size distribution for pinning pressure calculations. The gap between the two kinetics is non negligible.

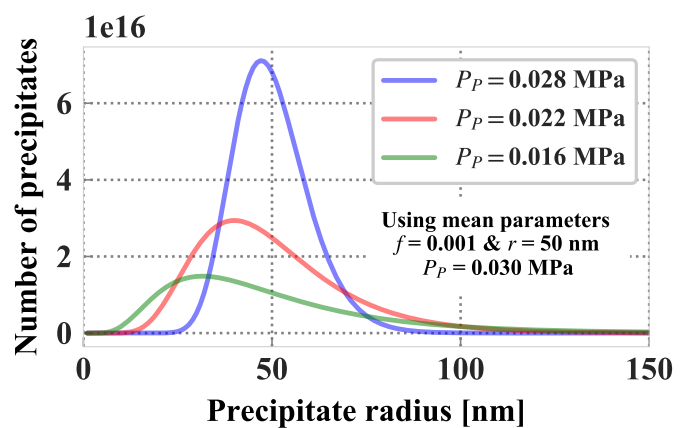

Figure 16: Comparison of the pinning pressure (Rios's expression) induced by three different size distributions of precipitates. The three size distributions present a mean radius of $50 \mathrm{~nm}$ and a mean volume fraction of 0.001 .

In order to investigate the effect of the distribution shape on grain growth kinetics, three different precipitate size distributions with exact same mean radius and volume fraction were compared (see figure 16). While a pinning pressure equal to 0.03 MPa was obtained (Rios's expression) using av- 
eraged parameters, the actual pinning pressures resulting from the three different size distributions can be significantly lower. For narrow size distribution the error remained small, but was significantly increases for wider size distributions. This error could be even greater in the case of more complex distributions such as multimodal ones. Taking account of the size distribution is therefore important for the calculation of pinning pressures.

The present grain growth model neglected the pinning effect of $\mathrm{TiN}$ and $\mathrm{Ti}_{4} \mathrm{C}_{2} \mathrm{~S}_{2}$. It was considered that only $(\mathrm{Ti}, \mathrm{Nb}) \mathrm{C}$ are small enough to be effective pinning particles. If it is reasonably assumed that $\mathrm{TiN}$ and $\mathrm{Ti}_{4} \mathrm{C}_{2} \mathrm{~S}_{2}$ have a mean radius of approximately $500 \mathrm{~nm}$, the pinning contributions of both populations can estimated to be $0.00175 \mathrm{MPa}$ using mean parameters. It represents approximately $7 \%$ of the initial pinning contribution of the $(\mathrm{Ti}, \mathrm{Nb}) \mathrm{C}$ population. Thus, the error resulting from not considering the pinning effect TiN and $\mathrm{Ti}_{4} \mathrm{C}_{2} \mathrm{~S}_{2}$ remains limited, especially for relatively short treatment times.

The modelling results were based on a solubility product calculated with Thermo-Calc under the assumptions that all $\mathrm{N}$ and $\mathrm{S}$ reacts entirely to form TiN and $\mathrm{Ti}_{4} \mathrm{C}_{2} \mathrm{~S}_{2}$, respectively. These two populations were not considered to evolve for all considered heat treatments. This hypothesis may sound slightly exaggerated for the highest temperatures, where $\mathrm{Ti}_{4} \mathrm{C}_{2} \mathrm{~S}_{2}$ have not been observed at $1280^{\circ} \mathrm{C}$. Slight amounts of Ti and C may be released in solid solution for the highest temperatures, increasing thus the stability domain of $(\mathrm{Ti}, \mathrm{Nb}) \mathrm{C}$. Therefore, the present model may not be accurate for temperatures above $1250{ }^{\circ} \mathrm{C}$.
However, using thermodynamic databases for all populations of precipitates without making any hypothesis leads to significantly different stability domains that come in contradiction with experiments. Using those calculations to estimate the solubility of each precipitate leads to a misrepresentation of the precipitation state for a given temperature. Thus, the CALPHAD approach provides a powerful framework for estimating solubility products, but needs to be used with caution.

\section{Conclusions}

In the present work, the evolution of the precipitation state and austenite grain growth were studied in a $\mathrm{Ti}-\mathrm{Nb}$ microalloyed steel during reversion treatments, i.e. starting from a fully precipitated state and performing thermal treatments between $950^{\circ} \mathrm{C}$ and $1250^{\circ} \mathrm{C}$.

- Based on acquired experimental data, a multiclass precipitation model was developed and used to predict the evolution of $(\mathrm{Ti}, \mathrm{Nb}) \mathrm{C}$ size distribution during thermal treatments.

- The resulting precipitate size distributions served as entry parameters to a simple grain growth model based on Zener pinning.

- The chemistry of the modeled alloy was modified to account for the amount of solute atoms actually available for precipitation, i.e. subtracting chemical elements already involved in existing and stable precipitates (TiN and $\left.\mathrm{Ti}_{4} \mathrm{C}_{2} \mathrm{~S}_{2}\right)$.

- Extensive SEM and TEM characterization leaded to similar initial precipitate size distri- 
butions, which served as initial distributions in the precipitation model.

- The chemistry and stability of $(\mathrm{Ti}, \mathrm{Nb}) \mathrm{C}$ precipitates was calculated from the TCFE8 thermodynamical database.

- Both precipitation and grain growth models did not contain any adjustable parameter, except the mobility factor $M_{0}$. All other model parameters were extracted either from thermodynamical databases or from literature.

- Accounting for the whole precipitation size distribution, rather than using average values, significantly influenced the calculated pinning pressure.

- The modeled austenite grain diameters were consistent with the experiments for all investigated heat treatments.

\section{Acknowledgements}

The authors gratefully acknowledge the funding received from the European Commission, Research Fund for Coal and Steel, under grant agreement 709803 (NANOFORM). Thanks are due to the CLYM (www.clym.fr) for access to the 2010F microscope, and to Nicholas Blanchard for access and help on the JEOL 2100 microscope.

\section{Declaration of interest}

Declarations of interest: none.

\section{References}

[1] T. Gladman and D. Dulieu. Grain-Size Control in Steels. Metal Science, 8(1):167-176, 1974.

[2] T. Gladman. Precipitation hardening in metals. Materials Science and Technology, 15(1):30-36, 1999.

[3] F. J. Humphreys, Gregory S. Rohrer, and Anthony D. Rollett. Recrystallization and related annealing phenomena. Elsevier, Amsterdam Oxford Cambridge, MA, third edition edition, 2017.

[4] P. R. Rios and D. Zllner. Grain growth unresolved issues. Materials Science and Technology, 34(6):629638, 2018.

[5] T. Gladman. The physical metallurgy of microalloyed steels. Number 792 in Book / The Institute of Materials. Maney, London, 2002.

[6] John W Cahn. The impurity-drag effect in grain boundary motion. Acta Metallurgica, 10(9):789-798, September 1962 .

[7] Emmanuel Hersent, Knut Marthinsen, and Erik Nes. On the Effect of Atoms in Solid Solution on Grain Growth Kinetics. Metallurgical and Materials Transactions $A, 45(11): 4882-4890,2014$.

[8] C. M. Sellars and J. A. Whiteman. Recrystallization and grain growth in hot rolling. Metal Science, 13(34):187-194, 1979.

[9] M Shome, O.P Gupta, and O.N Mohanty. A modified analytical approach for modelling grain growth in the coarse grain HAZ of HSLA steels. Scripta Materialia, 50(7):1007-1010, 2004.

[10] Seok-Jae Lee and Young-Kook Lee. Prediction of austenite grain growth during austenitization of low alloy steels. Materials E Design, 29(9):1840-1844, 2008.

[11] Yaowen Xu, Di Tang, Yong Song, and Xiaogang Pan. Prediction model for the austenite grain growth in a hot rolled dual phase steel. Materials \& Design (19802015), 36:275-278, 2012.

[12] S.S. Zhang, M.Q. Li, Y.G. Liu, J. Luo, and T.Q. Liu. The growth behavior of austenite grain in the heating process of $300 \mathrm{~m}$ steel. Materials Science and Engineering: $A, 528(15): 4967-4972,2011$.

[13] Geng-wei Yang, Xin-jun Sun, Qi-long Yong, Zhao-dong Li, and Xiao-xian Li. Austenite Grain Refinement and Isothermal Growth Behavior in a Low Carbon Vana- 
dium Microalloyed Steel. Journal of Iron and Steel Research, International, 21(8):757-764, 2014.

[14] I. Andersen and . Grong. Analytical modelling of grain growth in metals and alloys in the presence of growing and dissolving precipitatesI. Normal grain growth. Acta Metallurgica et Materialia, 43(7):2673-2688, 1995.

[15] P. A. Manohar, D. P. Dunne, T. Chandra, and C. R. Killmore. Grain Growth Predictions in Microalloyed Steels. ISIJ International, 36(2):194-200, 1996.

[16] Kumkum Banerjee, Matthias Militzer, Michel Perez, and Xiang Wang. Nonisothermal Austenite Grain Growth Kinetics in a Microalloyed X80 Linepipe Steel. Metallurgical and Materials Transactions A, 41(12):3161-3172, 2010.

[17] M. Maalekian, R. Radis, M. Militzer, A. Moreau, and W.J. Poole. In situ measurement and modelling of austenite grain growth in a $\mathrm{Ti} / \mathrm{Nb}$ microalloyed steel. Acta Materialia, 60(3):1015-1026, 2012.

[18] Mohammad Abdur Razzak, Michel Perez, Thomas Sourmail, Sophie Cazottes, and Marion Frotey. A Simple Model for Abnormal Grain Growth. ISIJ International, 52(12):2278-2282, 2012.

[19] Mohammad Abdur Razzak, Michel Perez, Thomas Sourmail, Sophie Cazottes, and Marion Frotey. Preventing Abnormal Grain Growth of Austenite in Low Alloy Steels. ISIJ International, 54(8):1927-1934, 2014.

[20] Richard Wagner, Reinhard Kampmann, and Peter W. Voorhees. Homogeneous Second-Phase Precipitation. In Gernot Kostorz, editor, Phase Transformations in Materials, pages 309-407. Wiley-VCH Verlag GmbH \& Co. KGaA, Weinheim, FRG, 2005.

[21] C Garca de Andres, F.G Caballero, C Capdevila, and D San Martin. Revealing austenite grain boundaries by thermal etching: advantages and disadvantages. Materials Characterization, 49(2):121-127, 2002.

[22] W. W. Mullins. Theory of Thermal Grooving. Journal of Applied Physics, 28(3):333-339, 1957.

[23] W. I. Halliday. Determination of the austenitic grain size of steel using a thermal etching method. ISI Special Report 81, Iron and Steel Institute, London, 1963.

[24] S. Béchet and L. Beaujard. Nouveau réactif pour la mise en vidence micrographique du grain austrénitique des aciers tremprés ou tremprés-revenus. Revue de Mtal- lurgie, 52(10):830-836, 1955.

[25] D. San Martín, Y. Palizdar, R.C. Cochrane, R. Brydson, and A.J. Scott. Application of Nomarski differential interference contrast microscopy to highlight the prior austenite grain boundaries revealed by thermal etching. Materials Characterization, 61(5):584-588, 2010.

[26] Johannes Schindelin, Ignacio Arganda-Carreras, Erwin Frise, Verena Kaynig, Mark Longair, Tobias Pietzsch, Stephan Preibisch, Curtis Rueden, Stephan Saalfeld, Benjamin Schmid, Jean-Yves Tinevez, Daniel James White, Volker Hartenstein, Kevin Eliceiri, Pavel Tomancak, and Albert Cardona. Fiji: an open-source platform for biological-image analysis. Nature Methods, 9(7):676-682, 2012.

[27] A. K. Giumelli, M. Militzer, and E. B. Hawbolt. Analysis of the Austenite Grain Size Distribution in Plain Carbon Steels. ISIJ International, 39(3):271-280, 1999.

[28] David B. Williams and C. Barry Carter. 22.4 ZContrast. In Transmission electron microscopy: a textbook for materials science. Springer, New York, 2. ed edition, 2009. OCLC: 254591841.

[29] Saulius Graulis, Daniel Chateigner, Robert T. Downs, A. F. T. Yokochi, Miguel Quirs, Luca Lutterotti, Elena Manakova, Justas Butkus, Peter Moeck, and Armel Le Bail. Crystallography Open Database an openaccess collection of crystal structures. Journal of Applied Crystallography, 42(4):726-729, 2009.

[30] J-O Andersson, Thomas Helander, Lars Hglund, Pingfang Shi, and Bo Sundman. Thermo-Calc \& DICTRA, computational tools for materials science. Calphad, 26(2):273-312, 2002.

[31] Thermo-calc software TCFE8 steels/fe-alloys database (accessed 30 july 2018).

[32] A. Schneider, C. Stallybrass, J. Konrad, A. Kulgemeyer, H. Meuser, and S. Meimeth. Formation of primary TiN precipitates during solidification of microalloyed steels Scheil versus DICTRA simulations. International Journal of Materials Research, 99(6):674-679, 2008.

[33] Xiaohong Yang, Dirk Vanderschueren, Jozef Dilewijns, Christian Standaert, and Yvan Houbaert. Solubility Products of Titanium Sulphide and Carbosul- 
phide in Ultra-low Carbon Steels. ISIJ International, 36(10):1286-1294, 1996.

[34] C.S. Smith. Introduction to Grains, Phases, and Interfacesan Interpretation of Microstructure. Trans. AIME, 175:15-51, 1948.

[35] B. R. Patterson and Y. Liu. Relationship between grain. Metallurgical Transactions A, 23(9):2481-2482, September 1992.

[36] P.R. Rios. On the relationship between pinning force and limiting grain radius. Scripta Materialia, 34(8):1185-1188, 1996.

[37] P.R. Rios and G.S. Fonseca. Grain boundary pinning by Al6mn precipitates in an Al1wt\%Mn alloy. Scripta Materialia, 50(1):71-75, 2004.

[38] P. R Rios and G. C. Fonseca. Grain Boundary Pinning by Particles. Materials Science Forum, 638-642:39073912, 2010.

[39] P. A. Manohar, M. Ferry, and T. Chandra. Five Decades of the Zener Equation. ISIJ International, 38(9):913-924, 1998.

[40] K. Huang and R.E. Log. Zener Pinning. In Reference Module in Materials Science and Materials Engineering. Elsevier, 2016.

[41] P.R. Rios. Overview no. 62: A theory for grain boundary pinning by particles. Acta Metallurgica, 35(12):2805-2814, 1987.

[42] M. Perez, M. Dumont, and D. Acevedo-Reyes. Implementation of classical nucleation and growth theories for precipitation. Acta Materialia, 56(9):2119-2132, 2008.

[43] M. Perez, M. Dumont, and D. Acevedo-Reyes. Corrigendum to Implementation of classical nucleation and growth theories for precipitation [Acta Materialia 56 (2008) 21192132]. Acta Materialia, 57(4):1318, 2009.

[44] Michel Perez. Gibbs-Thomson effects in phase transformations. Scripta Materialia, 52(8):709-712, 2005.

[45] Sangho Uhm, Joonoh Moon, Changhee Lee, Jihyun Yoon, and Bongsang Lee. Prediction Model for the Austenite Grain Size in the Coarse Grained Heat Affected Zone of Fe-C-Mn Steels: Considering the Effect of Initial Grain Size on Isothermal Growth Behavior. ISIJ International, 44(7):1230-1237, 2004.

[46] Thermo-calc software MOBFE3 steels/fe-alloys mobil- ity database (accessed 30 july 2018).

[47] A. Karmakar, S. Kundu, S. Roy, S. Neogy, D. Srivastava, and D. Chakrabarti. Effect of microalloying elements on austenite grain growth in $\mathrm{NbTi}$ and $\mathrm{NbV}$ steels. Materials Science and Technology, 30(6):653$664,2014$. 


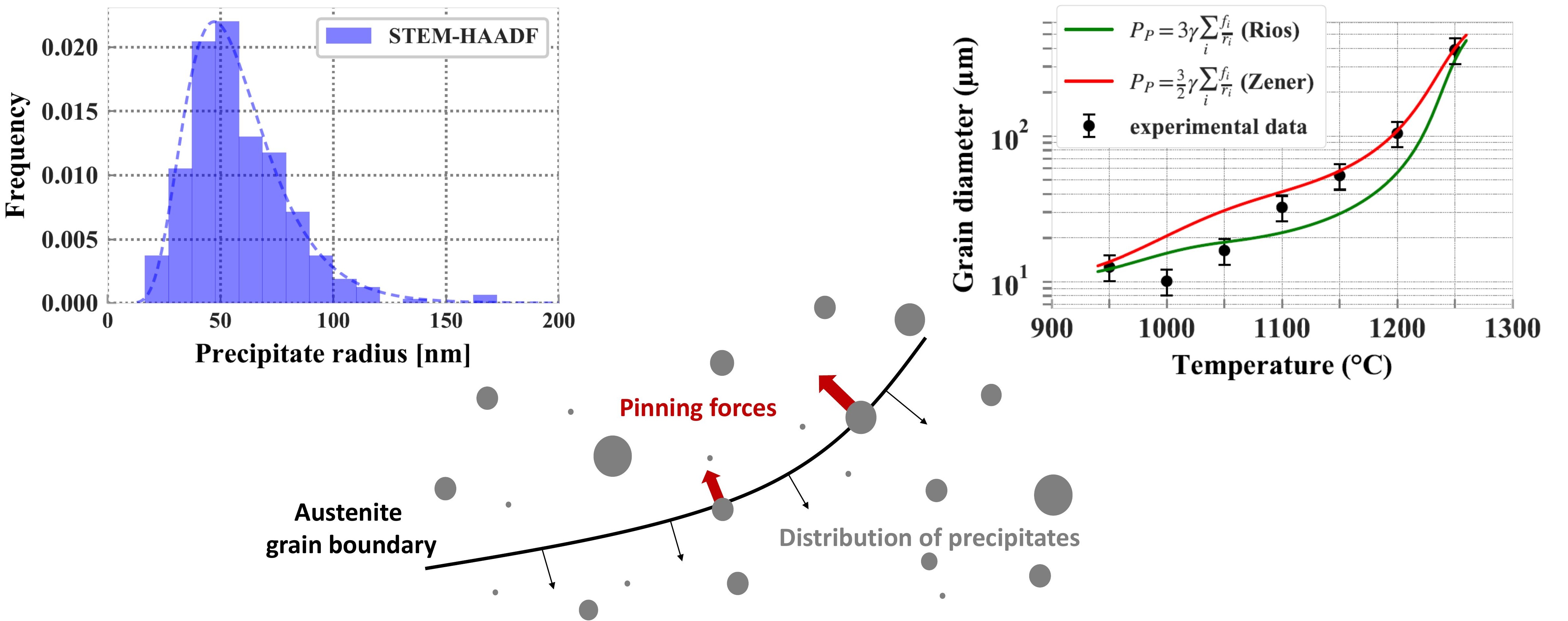

